\title{
Indoor Environmental Quality of Air Conditioned Residential Buildings in Extreme Dry Desert Climate
}

\author{
Farraj F. Al-Ajmi \\ Department of Civil Engineering, College of Technological Studies, Shuwaikh, Kuwait \\ Email: farraj2010@gmail.com
}

How to cite this paper: Al-Ajmi, F.F. (2018) Indoor Environmental Quality of Air Conditioned Residential Buildings in Extreme Dry Desert Climate. Journal of Power and Energy Engineering, 6, 86-97.

https://doi.org/10.4236/jpee.2018.68005

Received: July 26, 2018

Accepted: August 26, 2018

Published: August 29, 2018

Copyright $\odot 2018$ by author and Scientific Research Publishing Inc. This work is licensed under the Creative Commons Attribution International License (CC BY 4.0).

http://creativecommons.org/licenses/by/4.0/ Open Access

\begin{abstract}
In this study, the indoor environmental quality (IEQ) in air conditioned residential buildings in a dry desert climate is examined from the perspective of occupants via two aspects: thermal comfort and indoor air quality. The study presents statistical data about the domestic-occupant thermal comfort sensations together with data describing the indoor air quality in Kuwaiti residential buildings. With respect to the latter, the overall IEQ acceptance using two measurements namely: physical measurements and subjective information collected via questionnaires, was used to evaluate 111 occupants living in twenty five air-conditioned residential buildings in the state of Kuwait. The operative temperature based on Actual Mean Vote (AMV) and Predicted Mean Vote (PMV) was identified using linear regression analysis of responses on the ASHRAE seven-point thermal sensation scale and was found to be $25.2^{\circ} \mathrm{C}$ and $23.3^{\circ} \mathrm{C}$, respectively, in the summer season. Indoor air quality (IAQ) with respect to carbon dioxide concentration level was compared with the acceptable limits of international standards, i.e. ASHRAE Standard 62.1 [1]. The proposed overall IEQ acceptance findings in residential buildings show $\mathrm{CO}_{2}$ concentration level between 909 and $1250 \mathrm{ppm}$. However, this may be considered a higher level of $\mathrm{CO}_{2}$ concentration, which may require increasing ventilation rate through window operation or mechanical ventilation.
\end{abstract}

\section{Keywords}

Residential Buildings, Residential Indoor Environments, Indoor Air Quality, Thermal Comfort, Dry Desert Climates

\section{Introduction}

The achievement of a high quality indoor environment, whilst minimizing 
energy consumption in buildings is a key aim in most countries and is a particular challenge in a desert climate. People in different climates feel comfortable at different indoor air temperatures. Such temperatures can differ considerably from the values adopted by national energy codes, which in turn can impact upon space energy consumption in buildings with air conditioning systems, such as Kuwaiti residential buildings. Kuwait, as in most countries with an extreme dry-desert climate, has a long summer season with a mean daily maximum temperature of $46^{\circ} \mathrm{C}$ [2]. Centralized air-conditioning, which is generally deployed from the beginning of April to the end of October, accounts for around $75 \%$ of national electrical power consumption. Increasing the thermostat temperature setting in the summer season can potentially save significant electrical energy, which would, in turn, decrease energy expenditure, fossil fuel usage for generating electricity and consequently carbon dioxide emissions.

The indoor air temperature (or thermostat temperature) settings for all types of air-conditioned buildings and residential buildings in particular, are often calculated based on the analytical model developed by ISO 7730 [3]. This model, where comfort sensation is predicted via the Predicted Mean Vote (PMV), has been used, as the standard approach for thermal comfort evaluation. In addition, thermal comfort and IAQ studies have been carried out through AHSRAE standards [4] [5] to define comfort and prescribe ventilation procedures to provide acceptable indoor air quality. Sustainability for ASHRAE [5] means energy efficiency and healthy, productive indoor environments.

A large number of thermal comfort and indoor air quality (IAQ) studies have been conducted in buildings in all types of climates, most of which were carried out in tropical, subtropical and temperate climate zones [6] [7], while other studies were performed in cold climate zones [8] [9]. However, investigation of indoor thermal comfort and IAQ in buildings for countries located in dry desert climates is limited, although some studies can be mentioned for thermal comfort studies, as in [1] and [10]. Their results indicated that the Actual Mean Vote (AMV) of the occupants in air-conditioned buildings is greater than that of PMV. This may indicate that the ISO 7730 standard [3] for calculating PMV underestimates the individual's actual thermal sensation in a dry desert climate. However, most buildings in a desert climate like that of the state of Kuwait, where people spend most of their time (80\% - 90\%), are tightly enclosed spaces avoiding outdoor conditions. Such a situation, with poorly ventilated and tight buildings, increases the problems dealing with indoor air quality (IAQ), which thus, can have significant health effects as well as dissatisfaction on the occupants' thermal comfort sensation. In the study reported here, however, field experiments were conducted in twenty-five air-conditioned residential buildings, using survey questionnaires and physical measurements to collect data during the summers of 2014 and 2015.

The main objective of this paper is to investigate the indoor environmental quality (IEQ) in air conditioned residential buildings in a dry desert climate, 
which will be examined from the perspective of an occupant's acceptance in two aspects: thermal comfort and indoor air quality. This will provide significant information that can assist future policy aimed at enhancing IEQ and energy conservation, which may contribute to reducing carbon emissions.

\section{Thermal Environment}

\subsection{Indoor Thermal Comfort Assessments}

Twenty-five residential buildings were selected evenly over the five provinces of Kuwait (i.e. Capital, Hawalli, Aljahra, Alahamidi and Mobarak Alkabeir). The sizes of the selected buildings ranged from one to three floors with a plot area of $400 \mathrm{~m}^{2}$. Whilst it was impossible to cover all residential building types in Kuwait in this study, those buildings selected were considered from the perspective of the following specific criteria:

- Typical type, size and construction materials.

- Selected buildings are not older than 10 years and distributed evenly amongst the five provinces of Kuwait.

- Centralized air-conditioning with similar cooling size.

- Openings, i.e. windows, doors, etc., are closed completely in selected surveyed building during filed experiments.

- Buildings were selected based on the location schemes shown in Figure 1.

In this way, a reasonable sample of housing types from the Kuwaiti residential building stock is covered by this investigation.

First, confirm that you have the correct template for your paper size. This template has been tailored for output on the custom paper size $(21 \mathrm{~cm} \times 28.5$ $\mathrm{cm})$.

\subsection{Field Survey}

The template is used to format your paper and style the text. All margins, column widths, line spaces, and text fonts are prescribed; please do not alter them. You may note peculiarities. For example, the head margin in this template measures proportionately more than is customary. This measurement and others are deliberate, using specifications that anticipate your paper as one part of the entire journals, and not as an independent document. Please do not revise any of the current designations.

\subsection{Subjective Measurements}

The subjective study involved collecting data using questionnaires which were given to each subject to complete simultaneously with collection of the physical measurements in each residential building. The subjective questionnaires and a description of the experimental work procedure had been translated carefully into the Arabic language in order that the occupants could follow and understand. The questionnaire addressed the following areas: 1 ) background and personal information; 2) current clothing garments; 3 ) subjective thermal sensation 


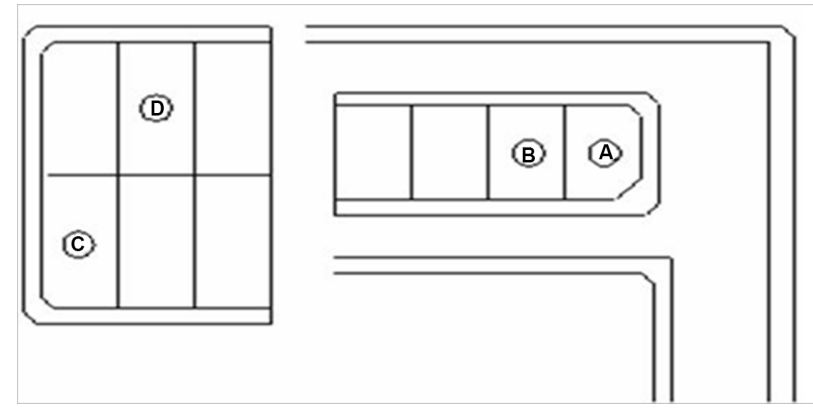

Figure 1. Residential building location schemes of A, B, D and C.

vote (the Actual Mean Vote, or AMV) based on the ASHRAE-seven point scale and consisting of: $(-3)$ cold, $(-2)$ cool, $(-1)$ slightly cool, (0) neutral, $(+1)$ slightly warm, (+2) warm, and (+3) hot); (iv) humidity sensation, scaled as: $(-3)$ very humid, $(-2)$ humid, $(-1)$ slightly humid, $(0)$ neither humid nor dry, $(+1)$ slightly dry, (+2) dry, and (+3) very dry. (v) Air movements' sensation scaled as: $(-3)$ very low, $(-2)$ low, $(-1)$ slightly low, (0) neither high nor low, (+1) slightly high, (+2) high, and (+3) very high.

The subjects were required to make only one choice from the scale for each question.

\subsection{Physical Measurements}

In addition to the subjective data collection, physical measurements were carried out in the 25 air-conditioned residential buildings using a Bruel \& Kjaer Indoor Climate Analyser Type 1212. The physical measurements included transducers to measure dry bulb and wet bulb air temperatures, relative humidity, air velocity, and operative temperature. The transducers and data logging system were fitted into a trolley arrangement to collect indoor climatic data at a height of 1.1 $\mathrm{m}$ above the floor, as specified by ISO 7730 (2005) [6] for a seated person. This was performed while respondents completed the questionnaires. A period of fifteen minutes was taken prior to the measurements survey to explain and demonstrate the procedure of the field experiments to the subjects in each building. This contributed to allowing the subjects to achieve a steady state thermal balance with their surroundings. The data collection period lasted for 75 minutes in each building. During this period, occupants were asked to sit in the living room, and were limited to light activity movement, such as body parts movements of hands, feet, neck etc. The metabolic rate value used in this study was estimated to be 1.2 met as recommended by ISO-7730 [3] for sedentary activity. Five sets of measurements were taken each at 15 -minute intervals.

\subsection{Clothing Description}

Indoor Kuwaiti clothing ensembles are different from those of outdoor ensembles in terms of their appearance, thickness and colours. A checklist of Kuwaiti male and female garments shown as photographs and descriptive schemes of ensembles was provided to the occupants at the time of completing the ques- 
tionnaire survey. A full description of male and female clothing ensembles and clothing insulation values were published in [11] and [12], and were coded in ISO 9920 [13]. However, the overall average clothing insulation values used in this study were estimated to be between $0.65-1.3$ clo, with a mean value of 0.9 clo, Table 1.

\subsection{Indoor Thermal Conditions}

Table 1 provides a summary of the personal data from the 111 occupants in the survey, together with their clothing insulation values. Data are presented as the mean of the family occupants in each of the 25 households. Indoor climate measurements for the 25 residential buildings are presented in Table 2. Indoor air temperature values ranged between $18.8^{\circ} \mathrm{C}-28.7^{\circ} \mathrm{C}$ with a mean value of $22.7^{\circ} \mathrm{C}$, and standard deviation of 0.8 , whilst recorded indoor relative humidities ranged from $33.2 \%-69.7 \%$ with a mean value of $43.5 \%$ and standard deviation of 1.97, Figure 2(a), Figure 2(b) show these data in histogram forms. Average indoor air movements varied between $0.01-0.38 \mathrm{~m} / \mathrm{s}$ with mean value of 0.13 $\mathrm{m} / \mathrm{s}$ and standard deviation of 0.03 , whilst operative temperatures were in the range $20.2^{\circ} \mathrm{C}-27.6^{\circ} \mathrm{C}$, with a mean of $23.71^{\circ} \mathrm{C}$ and standard deviation of 0.54 , Figure 2(a). Table 2 also provides statistical summaries of thermal environments and thermal indices of occupants, with actual mean votes (AMVs) ranging from -1.2 to +1.5 with a mean of -0.28 and standard deviation of -0.33 . Further analysis was conducted to find the indoor neutral temperature and thermal acceptability for the residential buildings, as may be shown in [1].

\section{Indoor Air Quality}

Despite the fact, indoor air quality is not considered directly as a thermal comfort parameter, it is greatly related issue. For instance, odour, airborne dust, suspended particles as well as low or high relative humidity in the space can be a source of discomfort. In addition, high relative humidity more than $70 \%$ may endorse moulds and fungi; on the other hand, relative humidity level less than $30 \%$ can be a cause of dryness of air inside the indoor environments. However, buildings in state of Kuwait, where people spend most of their time (80\% - 90\%), are tightly enclosed spaces avoiding outdoor conditions. Such a situation, with poorly ventilated and tight buildings, increases the problems dealing with Indoor Air Quality (IAQ), which thus, can have significant health impact as well as dissatisfaction on the occupants thermal comfort sensation. In addition, poor indoor air quality has major concern in recent years, particularly due to increase of number of reports of Sick Building Syndrome (SBS), which is associated with some symptoms such as: itchy eyes, skin irritation, etc. Also Odor is an indicator of poor indoor air quality and is often associated with level of carbon dioxide $\left(\mathrm{CO}_{2}\right)$ [1] [3]. However, in order to gain a closer insight into IAQ and thermal comfort for the indoor environment of each house, three steps were developed for the purposes of these measures [5], which are, as follows: 
Table 1. Occupants' personal data.

\begin{tabular}{|c|c|c|c|c|c|}
\hline House & Locations & $\begin{array}{c}\text { Age } \\
\text { (Mean) } \\
\mathrm{cm}\end{array}$ & $\begin{array}{c}\text { Height } \\
\text { (Mean) } \\
\text { cm }\end{array}$ & $\begin{array}{c}\text { Weight } \\
\text { (Mean) } \\
\text { kg }\end{array}$ & $\begin{array}{l}\text { Clothing } \\
\text { insulations } \\
\text { (Mean) }\end{array}$ \\
\hline 1 & $\mathrm{D}$ & 22.9 & 155 & 61.8 & 1.1 \\
\hline 2 & $\mathrm{D}$ & 36.2 & 162 & 70.7 & 0.72 \\
\hline 3 & $\mathrm{D}$ & 21.9 & 142.6 & 44.14 & 1.2 \\
\hline 4 & $\mathrm{D}$ & 27.5 & 163.5 & 74.7 & 1.2 \\
\hline 5 & $\mathrm{D}$ & 30.5 & 165.5 & 79 & 1.1 \\
\hline 6 & A & 44.5 & 168 & 84 & 0.98 \\
\hline 7 & C & 27.5 & 164.3 & 63.3 & 0.97 \\
\hline 8 & A & 26.7 & 146.7 & 57.7 & 0.93 \\
\hline 9 & $\mathrm{D}$ & 23.7 & 140.3 & 57.7 & 0.87 \\
\hline 10 & $\mathrm{D}$ & 26 & 165.5 & 70 & 0.88 \\
\hline 11 & $\mathrm{D}$ & 36.3 & 159.8 & 72.8 & 1 \\
\hline 12 & $\mathrm{D}$ & 39.5 & 166.8 & 68.2 & 0.78 \\
\hline 13 & $\mathrm{D}$ & 30 & 160 & 68.3 & 0.92 \\
\hline 14 & $\mathrm{D}$ & 39.5 & 166.5 & 71.5 & 0.88 \\
\hline 15 & A & 43 & 167 & 75.7 & 0.8 \\
\hline 16 & $\mathrm{D}$ & 32.8 & 173.7 & 68.7 & 0.7 \\
\hline 17 & $\mathrm{D}$ & 42 & 169.3 & 73.5 & 0.9 \\
\hline 18 & $\mathrm{D}$ & 30.3 & 138.7 & 60.3 & 0.78 \\
\hline 19 & C & 34.5 & 162.5 & 70.5 & 0.8 \\
\hline 20 & $\mathrm{D}$ & 32.7 & 159.5 & 75.8 & 0.8 \\
\hline 21 & $\mathrm{D}$ & 33.8 & 165.4 & 67.8 & 0.7 \\
\hline 22 & A & 32.4 & 153.6 & 73.6 & 1.1 \\
\hline 23 & $\mathrm{D}$ & 22.3 & 153.3 & 68.1 & 1.1 \\
\hline 24 & $\mathrm{D}$ & 37.8 & 168.7 & 75 & 0.7 \\
\hline 25 & C & 28.1 & 151.2 & 63.6 & 0.73 \\
\hline ALL & & 32.1 & 159.6 & 68.7 & 0.9 \\
\hline
\end{tabular}

Step 1: Walkthrough step.

Step 2: On-site data collections.

Step 3: Data analysis and evaluation.

The thermal environment and comfort survey was carried out in 25 residential buildings across the five provinces of Kuwait. A total of 111 subjects providing 111 sets of physical measurements, and questionnaires were used to collect subjective data. The subjects consisted of 58 (52\%) males and 53 (48\%) females. The age of the inhabitants ranged from 12 to 65 years, with a mean age of 32.1 years. Their mean height was $159.6 \mathrm{~cm}$ and their mean weight was $68.7 \mathrm{~kg}$, Table 1. The fieldwork was carried out in the State of Kuwait during the summer 
Table 2. Summary of statistical results for mean indoor environmental parameters of 25 air-conditioned residential buildings in Kuwait.

\begin{tabular}{|c|c|c|c|c|c|}
\hline House & Locations & $\begin{array}{c}\text { Age } \\
\text { (Mean) } \\
\text { cm }\end{array}$ & $\begin{array}{c}\text { Height } \\
\text { (Mean) } \\
\text { cm }\end{array}$ & $\begin{array}{c}\text { Weight } \\
\text { (Mean) } \\
\text { kg }\end{array}$ & $\begin{array}{c}\text { Clothing } \\
\text { insulations } \\
\text { (Mean) }\end{array}$ \\
\hline 1 & $\mathrm{D}$ & 22.9 & 155 & 61.8 & 1.1 \\
\hline 2 & $\mathrm{D}$ & 36.2 & 162 & 70.7 & 0.7 \\
\hline 3 & $\mathrm{D}$ & 21.9 & 142.6 & 44 & 1.2 \\
\hline 4 & $\mathrm{D}$ & 27.5 & 163.5 & 74.7 & 1.2 \\
\hline 5 & $\mathrm{D}$ & 30.5 & 165.5 & 79 & 1.1 \\
\hline 6 & A & 44.5 & 168 & 84 & 0.9 \\
\hline 7 & C & 27.5 & 164.3 & 63.3 & 0.9 \\
\hline 8 & A & 26.7 & 146.7 & 57.7 & 0.9 \\
\hline 9 & $\mathrm{D}$ & 23.7 & 140.3 & 57.7 & 0.8 \\
\hline 10 & $\mathrm{D}$ & 26 & 165.5 & 70 & 0.8 \\
\hline 11 & D & 36.3 & 159.8 & 72.8 & 1 \\
\hline 12 & D & 39.5 & 166.8 & 68.2 & 0.8 \\
\hline 13 & $\mathrm{D}$ & 30 & 160 & 68.3 & 0.9 \\
\hline 14 & $\mathrm{D}$ & 39.5 & 166.5 & 71.5 & 0.9 \\
\hline 15 & A & 43 & 167 & 75.7 & 0.8 \\
\hline 16 & D & 32.8 & 173.7 & 68.7 & 0.7 \\
\hline 17 & D & 42 & 169.3 & 73.5 & 0.9 \\
\hline 18 & $\mathrm{D}$ & 30.3 & 138.7 & 60.3 & 0.9 \\
\hline 19 & $\mathrm{C}$ & 34.5 & 162.5 & 70.5 & 0.8 \\
\hline 20 & $\mathrm{D}$ & 32.7 & 159.5 & 75.8 & 0.8 \\
\hline 21 & $\mathrm{D}$ & 33.8 & 165.4 & 67.8 & 0.7 \\
\hline 22 & A & 32.4 & 153.6 & 73.6 & 1.1 \\
\hline 23 & D & 22.3 & 153.3 & 68.1 & 1.1 \\
\hline 24 & D & 37.8 & 168.7 & 75 & 0.7 \\
\hline 25 & C & 28.1 & 151.2 & 63.6 & 0.7 \\
\hline ALL & & 32.1 & 159.6 & 68.7 & 0.9 \\
\hline
\end{tabular}

season using the following survey procedures. Note that, due to cultural requirements, it was necessary that the survey be conducted by a female experimenter.

\subsection{Walkthrough (Step 1)}

The first and most critical step of IAQ investigation for preparing of data analysis and evaluation (step 3) of a building is walkthrough inspections. This method can help to clarify the most critical areas of the house design and may help to develop detailed on-site data collections (step 2). 


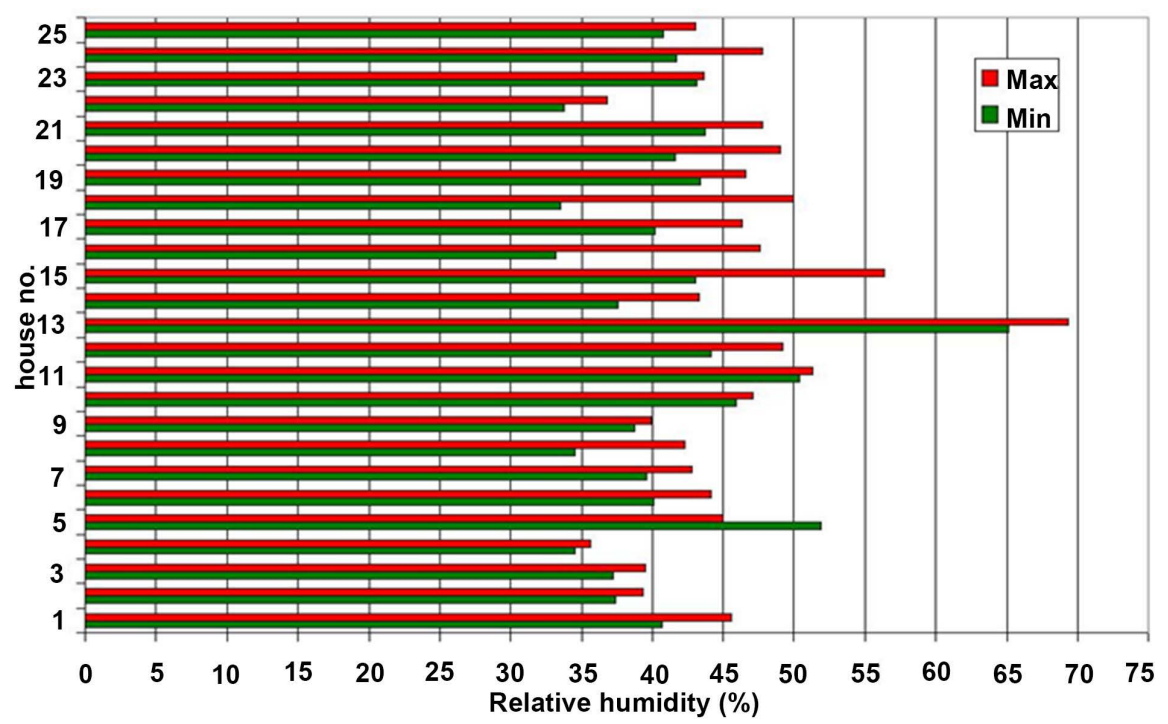

(a)

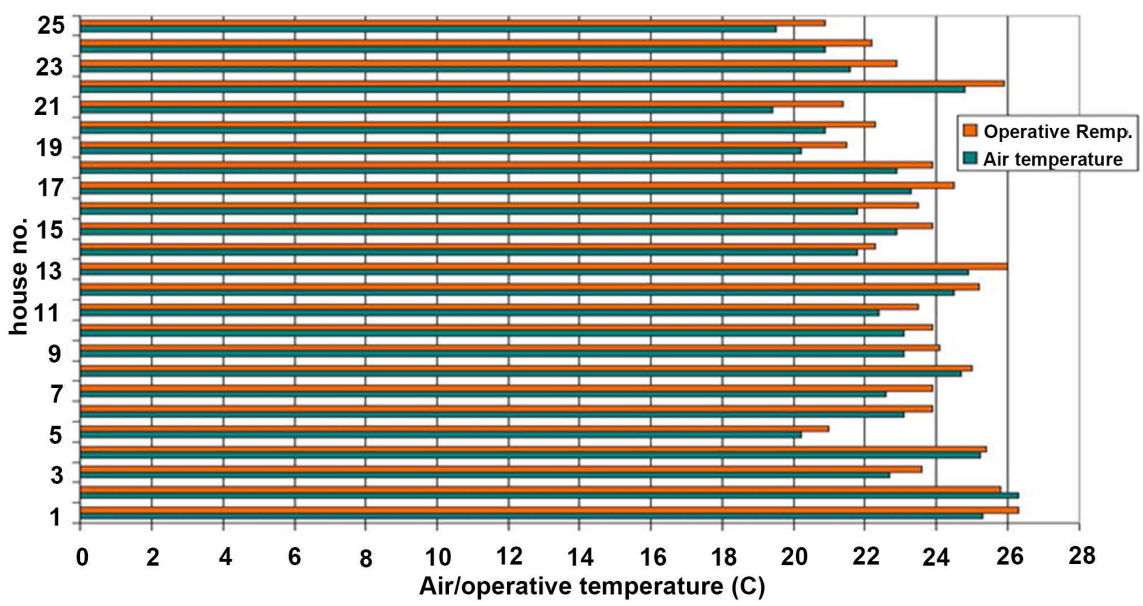

(b)

Figure 2. (a) Min-Max Relative humidity and (b) Indoor mean air temperature and operative temperature, for all residential buildings.

\subsection{On-Site Data Collections (Step 2)}

Measurements of $\mathrm{CO}_{2}$ concentrations level were carried out at different locations in the occupied zone within each house during occupant's thermal comfort sensation measures. Three sampling points were selected in the occupied space with point 4 in an outdoor location. These measurements were performed as the respondents completing the thermal comfort questionnaires and during the data collection period. In addition to carbon dioxide concentration $\mathrm{CO}_{2}$ measurements, air temperature, relative humidity and air velocity were measured at 5 min intervals which lasted for approximately $75 \mathrm{~min}$ for each house.

\subsection{Data Analysis and Assessment}

The collected data of IAQ are analyzed, based on the Concentration of carbon dioxide $\left(\mathrm{CO}_{2}\right)$ measures. Measured values of thermal comfort parameters are 
analyzed as in section 2 and tabulated as shown in Table 1, Table 2 and Table 3. In this section, measurements of $\mathrm{CO}_{2}$ Concentration levels can be considered as an indicator of fresh air required in the space in terms of ventilation rate [5]. Table 4 gives for each house; mean concentrations of $\left(\mathrm{CO}_{2}\right)$, minimum, maximum, and standard deviation. The $\left(\mathrm{CO}_{2}\right)$ monitoring shows that concentrations vary from house to house and may be changed according to A/C type used, air tightness of enclosed space, window operation etc, and building location. The Concentration levels of $\left(\mathrm{CO}_{2}\right)$ were measured using a GE Telaire 7001 $\mathrm{CO}_{2}$ /Temperature Monitor.

The results of indoor $\mathrm{CO}_{2}$ concentration levels for the surveyed Kuwaiti houses are between $598 \mathrm{ppm}$, as the lowest value and $1252 \mathrm{ppm}$ as a highest value. However, $\mathrm{CO}_{2}$ concentration for Zone D (house no. 24) exhibits higher mean concentration levels. The mean values in Zone D ranged between $790 \mathrm{ppm}$ and $1250 \mathrm{ppm}$, while that in Zone A exhibits lower mean concentration level range ina between $598 \mathrm{ppm}$ and $720 \mathrm{ppm}$. Meanwhile, the higher and lower $\mathrm{CO}_{2}$ concentration levels for zone B (house no. 9) are 710 ppm and 935 ppm respectively, while that for zone C are 715 ppm (house no. 7) and 842 ppm (house no. 19) respectively.

Taken as a whole, the mean concentration levels of $\mathrm{CO}_{2}$ in the buildings located in zone $\mathrm{D}$ is $42.6 \%$ higher than that in the buildings of zone $\mathrm{A}$. As may be seen from Figure 1, the buildings located in zone A are detached building, which are location is open toward the street from three sides, promoting in leakage and dilution of outdoor air when windows are open. However, buildings located in zone $\mathrm{D}$ are attached to other buildings from three sides and open to the street from only one side, which may cause them to be affected less with outdoor fresh air. However, the mean $\mathrm{CO}_{2}$ concentration level values of all surveyed buildings show that house no. 16 exhibits the highest value equal to $994 \mathrm{ppm}$, while that for house no. 6 exhibits the lowest value equal to $706 \mathrm{ppm}$. Thus, air-conditioned residential buildings in Kuwait during summer season are in spite of that, within the criteria limits of 1000 ppm, Table 4. However, air-conditioned residential buildings located as zone of $\mathrm{D}$ exhibit higher $\mathrm{CO}_{2}$ concentration levels, which may require an engineer/architect to consider increasing the ventilation rate through window operation or may be using mechanical ventilation.

\section{Conclusions}

The main objective of this study was to investigate the indoor environmental quality (IEQ) in air conditioned residential buildings in a dry desert climate in

Table 3. Thermal acceptability of all subjects living in the residential buildings.

\begin{tabular}{cccc}
\hline \multirow{2}{*}{ Sensation vote range } & \multicolumn{3}{c}{ Thermal preference scales: } \\
\cline { 2 - 4 } & Warmer & No change & Cooler \\
\hline$-3,-2$ & $34.6 \%$ & $54 \%$ & $11.5 \%$ \\
$-1,0,+1$ & $22 \%$ & $67 \%$ & $11.5 \%$ \\
$+3,+2$ & 0 & $30 \%$ & $70 \%$ \\
\hline
\end{tabular}


Table 4. $\mathrm{CO}_{2}$ concentrations for each set of measurements.

\begin{tabular}{|c|c|c|c|c|c|}
\hline \multirow{2}{*}{ House no. } & \multirow{2}{*}{ Location } & \multicolumn{4}{|c|}{$\mathrm{CO}_{2}$ Concentration } \\
\hline & & Min. & Max. & STD & Mean \\
\hline 1 & $\mathrm{D}$ & 812 & 1126 & 138.2 & 930 \\
\hline 2 & $\mathrm{D}$ & 805 & 1145 & 148.9 & 921 \\
\hline 3 & $\mathrm{D}$ & 758 & 995 & 105.9 & 900 \\
\hline 4 & $\mathrm{D}$ & 825 & 981 & 64.07 & 920 \\
\hline 5 & $\mathrm{D}$ & 840 & 1165 & 154.5 & 985 \\
\hline 6 & A & 688 & 730 & 16.8 & 706 \\
\hline 7 & $\mathrm{C}$ & 715 & 835 & 49.3 & 799 \\
\hline 8 & A & 685 & 720 & 13.5 & 708 \\
\hline 9 & B & 710 & 935 & 90.9 & 861 \\
\hline 10 & $\mathrm{D}$ & 818 & 1138 & 134.4 & 987 \\
\hline 11 & $\mathrm{D}$ & 790 & 937 & 59.8 & 873 \\
\hline 12 & $\mathrm{D}$ & 823 & 980 & 65.8 & 923 \\
\hline 13 & $\mathrm{D}$ & 826 & 964 & 56.4 & 900 \\
\hline 14 & $\mathrm{D}$ & 779 & 987 & 88.1 & 920 \\
\hline 15 & A & 598 & 804 & 74.9 & 717 \\
\hline 16 & $\mathrm{D}$ & 887 & 1140 & 92.2 & 994 \\
\hline 17 & $\mathrm{D}$ & 830 & 945 & 44.5 & 902 \\
\hline 18 & $\mathrm{D}$ & 801 & 931 & 57.7 & 851 \\
\hline 19 & $\mathrm{C}$ & 717 & 842 & 52.5 & 770 \\
\hline 20 & $\mathrm{D}$ & 816 & 942 & 45.5 & 884 \\
\hline 21 & $\mathrm{D}$ & 909 & 931 & 9.1 & 920 \\
\hline 22 & A & 687 & 732 & 20.1 & 714 \\
\hline 23 & $\mathrm{D}$ & 869 & 968 & 43.9 & 911 \\
\hline 24 & $\mathrm{D}$ & 827 & 1250 & 175.7 & 966 \\
\hline 25 & $\mathrm{C}$ & 728 & 761 & 13.8 & 748 \\
\hline
\end{tabular}

terms of thermal comfort and indoor air quality. A total of 111 occupants in twenty-five air-conditioned residential buildings located in the dry desert climate of Kuwait were surveyed during the summers of 2014 and 2015. The survey involved the recording of environmental parameters and human thermal comfort responses. The residential buildings were evenly distributed across the five provinces of Kuwait. The main findings of this study may be used as a quantitative assessment criterion for indoor Kuwaiti residential environments as well as development of future energy-related design codes. The main results of this study were as follows:

- The level of carbon dioxide $\mathrm{CO}_{2}$ monitoring shows that concentrations vary from house to house and may be changed according to A/C type, windows 
operation, air tightness of building space and building location.

- The concentration levels of $\mathrm{CO}_{2}$ for the surveyed Kuwaiti houses are between $548 \mathrm{ppm}$ and $1250 \mathrm{ppm}$.

- Across all residential buildings, the mean concentration levels of $\mathrm{CO}_{2}$ in buildings located in zone $\mathrm{D}$, which are attached to the other buildings from three sides, are $42.6 \%$ higher than those in the buildings of zone $\mathrm{A}$, which are detached buildings open toward the street from three sides, promoting in leakage and dilution of outdoor air when windows are open.

- Air-conditioned residential buildings located in zone $\mathrm{D}$ exhibit higher $\mathrm{CO}_{2}$ concentration levels, which may require an engineer/architect to consider increasing the ventilation rate through window operation or may be using mechanical ventilation.

- Across all residential buildings, the mean indoor dry-bulb air temperature was found to be $22.7^{\circ} \mathrm{C}$ with standard deviation of 0.8 and mean relative humidity of $43.5 \%$ with standard deviation of 1.97 and a mean air movement of $0.13 \mathrm{~ms}^{-1}$, with standard deviation of 0.03 .

- The neutral operative temperature for occupants was found to be $25.2^{\circ} \mathrm{C}$. This was obtained by linear regression analysis of actual mean vote on operative temperature.

\section{Acknowledgements}

This work was financially supported by the Kuwait Foundation for the Advancement of Sciences (KFAS) under research grant (2004-1508-02), this support being gratefully acknowledged.

\section{Conflicts of Interest}

The authors declare no conflicts of interest regarding the publication of this paper.

\section{References}

[1] Al-Ajmi Farraj, F. and Loveday, D.L. (2010) Indoor Thermal Conditions and Thermal Comfort in Air-Conditioned Domestic Buildings in the Dry-Desert Climate of Kuwait. Building and Environment, 45, 704-710. https://doi.org/10.1016/j.buildenv.2009.08.018

[2] Kuwait International Airport. (2006) Meteorological Summaries Year 1962-2006, State of Kuwait: Meteorological Department Climatological Division.

[3] ISO 7730. (2005) Moderate Thermal Environments. Determination of the PMV and PPD Indices and Specification of the Conditions for Thermal Comfort. 2nd Ed., International Organisation for Standardisation, Geneva.

[4] ANSI/ASHRAE, Standard 55. (2004) Thermal Environmental Conditions for Human Occupancy. American Society of Heating, Refrigerating and Air-Conditioning Engineers, Inc., Atlanta, Georgia.

[5] ANSI/ASHRAE Standard 62.1. (2007) Ventilation for Acceptable Indoor Air Quality. American Society of Heating. Refrigerating and Air-Conditioning Engineers, Inc., Atlanta, Georgia. 
[6] Sekhar, C. and Ching, C.S. (2002) Indoor Air Quality and Thermal Comfort Studies of an Under-Floor Air-Conditioning System in the Tropics. Energy and Buildings, 34, 431-444. https://doi.org/10.1016/S0378-7788(01)00128-1

[7] Mallick, F.H. (1996) Thermal Comfort and Building Design in the Tropical Climates. Energy and Buildings, 23, 161-167. https://doi.org/10.1016/0378-7788(95)00940-X

[8] Howell, W.C. and Kennedy, P.A. (1979) Field Validation of the Fanger Thermal Comfort Model. Human Factors, 21, 229-239. https://doi.org/10.1177/001872087902100211

[9] Busch, J.F. (1990) Thermal Responses to the THAI Office Environment. ASHRAE Transactions, 96, 859-872.

[10] Cena, K. and de Dear, R.J. (2001) Thermal Comfort and Behavioural Strategies in Office Buildings Located in a Hot-Arid Climate. Journal of Thermal Biology, 26, 409-414. https://doi.org/10.1016/S0306-4565(01)00052-3

[11] Al-Ajmi, F., Loveday, D.L., Bedwell, K.H. and Havenith, G. (2008) Thermal Insulation and Clothing Area Factors of Typical Arabian Gulf Clothing Ensembles for Males and Females: Measurements Using Thermal Manikins. Applied Ergonomics, 39, 407-414. https://doi.org/10.1016/j.apergo.2007.10.001

[12] Al-Ajmi, F., Loveday, D.L. and Havenith, G. (2006) Thermal Insulation of Arabian Gulf Male Clothing: Measurements Using a Thermal Manikin. ASHRAE Transactions, 112, 240-246.

[13] ISO 9920. (2006) Ergonomics of the Thermal Environment-Estimation of the Thermal Insulation and Evaporative Resistance of Clothing. International Standard Organization for Standardization (ISO). 